\title{
A qualidade sócioambiental em assentamentos rurais do Rio Grande do Norte, Brasil
}

\author{
The socio-environmental quality of rural settlements in Rio Grande do Norte State, northeastern Brazil
}

\author{
Kilvia Kalidia Sales de LimaI Priscila Fabiana Macedo Lopes ${ }^{\text {II }}$
}

RESUMO

O processo de Reforma Agrária é oferecido como uma possível estratégia para redução da pobreza e aumento da equidade social, mas depende de políticas públicas eficientes, tornando os agricultores beneficiados auto-sustentáveis. Objetivando apresentar as principais problemáticas socioambientais de 33 assentamentos rurais do Rio Grande do Norte (nordeste brasileiro), foram avaliados aspectos sociais, econômicos e ambientais de 631 famílias desses assentamentos e de 16 relatórios PRAD (Plano de Recuperação de Áreas Degradadas) do período de 2007 a 2010. Observou-se que a emancipação de um assentamento, medida através da geração de renda, grau de escolaridade e mudanças de hábitos ambientais, não está ligada ao seu tempo de fundação, e que a sua renda pouco depende da agricultura, sendo afetada principalmente pela proximidade de centros urbanos, pelo número de aposentados na família e pela participação em programas sociais. Os dados ambientais apontam o baixo nível de escolaridade e a maior idade dos assentamentos como fatores determinantes para o aumento da degradação das Reservas Legais e Áreas de Proteção Permanentes. Esses dados sugerem que o processo de Reforma Agrária ainda é deficiente na região nordeste, não priorizando a independência social dos assentamentos e ignorando a sua temática ambiental.

Palavras-chave: políticas públicas, reforma agrária, código florestal, indicadores socioecológicos.

\section{ABSTRACT}

The Brazilian land reform is a possible strategy to reduce poverty and increase social equality, but it depends on efficient public policies capable of making the peasants selfsustainable. With the goal of presenting the main socio-economic challenges of 33 rural settlements of former landless peasants in Rio Grande do Norte State (Northeastern Brazil), we evaluated socio, economic and environmental aspects of 631 families from these settlements and 16 "Restoration Plan for Degraded Areas" (PRAD), prepared between 2007 and 2010. The emancipation of a settlement, measured through income generation, schooling level, and changes in people's environmental habits, was not related to the age of the settlement. Also, the income of a settlement is hardly dependent on agriculture, being mostly affected by distance from urban centers, number of retired people in the household and participation in social programs. Low schooling level and aging of the settlement are determinant factors in the increase of deforestation of Legal Reserves and Areas of Permanent Protection. These data suggest than land reform is still deficient in the Brazilian northeast; it does not prioritize the socioeconomic independence of the settlements and ignore their environmental situation.

Key words: public policies, land reform, forest law, socioecological indicators.

\section{INTRODUÇÃO}

Ao longo dos anos, o processo de Reforma Agrária tem se tornado peça fundamental nos avanços econômicos e sociais, apresentando estratégias positivas na redução da pobreza e aumento da equidade social (CARDOSO, 2004). No mundo, diversas experiências surtiram efeitos satisfatórios no desenvolvimento rural, destacando-se países desenvolvidos como os Estados Unidos e o Japão. Em comum, a reforma agrária no mundo visa ao fortalecimento da agricultura familiar e ao acesso à terra (GUANZIROLI, 2001).

ICentro de Apoio ao Desenvolvimento Sustentável do Semi-Árido (ONG Cactus), 62280-000, Santa Quiteria, CE, Brasil.

"Departamento de Botânica, Ecologia e Zoologia, Universidade Federal do Rio Grande do Norte (UFRN), 59078-900, Natal, RN, Brasil. E-mail: priscila@cb.ufrn.br. *Autor para correspondência. 
Poucos são os estudos que analisam a melhoria de vida do camponês contemplado pela reforma agrária, especialmente os que consideram as variações regionais (GUANZIROLI, 1994; MAFIOLETTI, 1997). O estudo de SPAROVEK (2003) se destaca como um dos mais abrangentes, tendo como viés a qualidade de vida do assentado, que envolve as questões ambientais, sociais e econômicas. Seus resultados apontam que, em termos quantitativos, a intervenção fundiária é significativa, mas, quando analisadas em uma ótica mais específica, a qualidade do processo mostra-se ainda fragilizado, já que muitos sofrem com a falta de escolas, casa, abastecimento de água, tratamento de esgoto, atendimento médico e transporte (SPAVOREK, 2003).

Muito se tem discutido sobre as alternativas que promovam uma agricultura familiar sustentável dentro do processo de assentamento rural, garantindo segurança alimentar, melhoria de renda e minimização dos impactos ambientais (ALMEIDA, 1998). Essas alternativas se contrapõem às medidas anteriores, que tentavam acompanhar o ritmo proposto pela revolução verde, como a monocultura, a utilização de agrotóxicos, insumos artificiais, a queima e o desmatamento descontrolado. Nesse sentido, são essenciais políticas públicas eficientes, que possibilitem a qualificação profissional, o apoio técnico, financeiro e estrutural, ampliando o universo do campo, de forma que os assentamentos se tornem competitivos e autosustentáveis (GEHLEN, 2004).

Considerando esse panorama, este estudo objetiva apresentar os principais problemas que dificultam a sustentabilidade e a consequente emancipação de assentamentos rurais no Rio Grande do Norte, nordeste brasileiro. Foca-se aqui na capacidade de geração de rendas desses assentamentos (aspecto econômico), seu nível educacional (aspecto social) e nos níveis de desmatamento de áreas de proteção permanente e de reserva legal, além da forma como esses assentamentos lidam com seus resíduos (aspectos ambientais).

\section{MATERIAL E MÉTODOS}

Área de estudo e o projeto INCRA - ambiental

Este estudo baseou-se nos dados obtidos através do projeto "Diagnóstico e Recuperação Ambiental das Áreas de Reserva Legal e de Áreas de Preservação Permanente de Projetos de Assentamento do INCRA-RN" (INCRA Ambiental, 2007 a 2010), promovido pelo Instituto Nacional de Colonização e Reforma Agrária (INCRA) em parceria com a Universidade Federal do Rio Grande do Norte (UFRN).
Este projeto abrangeu 33 assentamentos habitados por 778 famílias, distribuídos por todo o estado. Neste trabalho, foram avaliados os recursos geológicos, biológicos e hídricos da região, identificando a área da Reserva Legal (RL) e a existência de Áreas de Preservação Permanentes (APP), para gerar o Plano de Recuperação de Áreas Degradadas (PRAD). Foram ainda aplicados questionários para identificar o perfil socioeconômico-ambiental das famílias assentadas; além de levantamento do histórico do assentamento e da existência de fomentos fornecidos por órgãos públicos e privados.

Metodologia

Utilizaram-se as entrevistas do projeto INCRA-Ambiental, baseadas em questionários com perguntas estruturadas, aplicadas a $81,1 \%$ das famílias $(\mathrm{n}=631)$. Foram utilizados também 16 relatórios PRAD (todos que haviam sido concluídos até novembro de 2010), para a retirada do percentual de degradação da RLe da APP.

Para verificar possíveis indicadores de sustentabilidade, foram calculadas primeiramente as médias das seguintes variáveis por assentamento: 1número de beneficiários do Bolsa Família; 2- número de assalariados; 3- número de atividades de subsistência; 4- número de beneficiários atendidos por outros Programas Sociais; 5- número de aposentados na família; 6- número de cultivos; 7- número de animais de pequeno porte (aves) criados e de grande porte (bovino, suíno, caprino e ovino); e 8- número de beneficiários que queimam o lixo ou dispõe de outras formas para descartálo. Algumas variáveis foram coletadas dentro de categorias ao invés de valores específicos (ex.: escolaridade e renda da família), o que exigiu a criação de um escore para as análises. Por exemplo, assentados que recebem até meio salário mínimo pontuaram 1 , entre meio e um salário pontuaram 2 , acima de um e abaixo de dois salários pontuaram 3, e acima de dois salários pontuaram 4. Da mesma forma foi feito para educação, considerando-se desde analfabetos até ensino superior completo. Idade do assentamento e distância do assentamento (em $\mathrm{km})$ até o centro urbano do seu município foram variáveis retiradas do levantamento do histórico de cada assentamento.

\section{Análises estatísticas}

Foram realizadas Regressões Lineares para verificar se quanto mais antigo um assentamento (idade $=$ variável independente), maior a renda familiar ou a produção (medida pela criação de animais de grande e pequeno porte, e cultivos agrícolas). Buscou-se investigar se existia relação entre a idade do assentamento e a 
obtenção de recursos financeiros, tais como o número de assalariados, aposentados, existência de trabalho de subsistência, Bolsa Família e demais programas sociais, através de Correlações de Spearman. A investigação de indicadores ambientais foi realizada através de duas análises. Na primeira delas, usou-se a Correlação de Spearman para verificar se coletas de lixo se tornam mais comuns conforme os assentamentos se aproximam dos centros urbanos, onde se presume a existência de maior infraestrutura. O mesmo tipo de correlação foi também utilizado para investigar se assentamentos mais antigos teriam práticas mais sustentáveis, em um gradiente que variou de jogar o lixo a céu aberto, queimar, enterrar ou entregar para a coleta.

Utilizaram-se regressões lineares múltiplas em que se esperava encontrar fatores que explicassem as variações na 1) renda média de um assentamento; 2) percentual de degradação da RL; e 3) percentual de degradação da APP dos assentamentos. As variáveis explanatórias utilizadas para investigar a renda média do assentamento (INC) foram (entre parênteses são mostrados os símbolos atribuídos a cada variável): idade do assentamento (AGE), distância do centro urbano (DIST), número médio de cultivos existentes (cultivos comerciais) (CP), número médio de animais de grande porte $(\mathrm{LH})$, número médio de animais de pequeno porte $(\mathrm{SH})$, número médio de aposentados pensionistas no assentamento (RT) e número médio de famílias recebendo o auxílio Bolsa Família (SW) (equação abaixo).

$I N C=u+A G E+D I S T+C P+L H+S H+$

$R T+S W$, no qual $u$ representa o intercepto.

As variáveis explanatórias utilizadas para investigar o percentual de degradação da RL (LRD) e da APP (PPD) foram: idade do assentamento (AGE), distância do centro urbano (DIST), escolaridade média dos assentados (SCH) e renda média dos assentados (INC):

$$
L R D=u+A G E+D I S T+S C H+I N C, \text { no }
$$

qual $u$ representa o intercepto.

$P P D=u+A G E+D I S T+S C H+I N C$, no

qual $u$ representa o intercepto.

Na realização dos testes paramétricos, os dados foram transformados em $\log _{\mathrm{n}}$ e tiveram sua normalidade checada pelo teste de Shapiro Wilk.

\section{RESULTADOS E DISCUSSÃO}

Em apenas cinco (15,2\%) assentamentos, há escolas até o ensino fundamental e nenhum possui escolas de nível médio. A maioria dos beneficiários $(44,0 \%)$ é analfabeta, $35,2 \%$ cursaram até o Ensino Fundamental I, 13,2\% até oEnsino Fundamental II, 7,0\% chegaram a fazer o Ensino Médio e três assentados informaram ter curso superior. Arenda das comunidades estudadas é altamente variável, devido à disponibilidade de emprego e sazonalidade dos recursos cultivados, o que possibilitou apenas uma estimativa: $25,8 \%$ alegaram produzir até meio salário mínimo ao mês, $34,7 \%$ afirmaram ter uma renda de até um salário mínimo, 30,2\% dizem ganhar entre um e dois salários mínimos e somente 9,3\% dizem gerar uma renda acima de dois salários (valor do salário mínimo em novembro de 2010: $\mathrm{R} \$ 465,00$ - equivalente a US $\$ 292,88$, valor do dólar em 09/06/2011). Em outras regiões do país, como Sul e Sudeste, assentados tendem a ter escolaridade e rendas ligeiramente mais altas, enquanto Norte e Nordeste, além de deficitárias em educação e renda, mostram-se com menor acesso à infraestrutura, saúde e créditos (BERGAMASCO, 1997).

Boa parte dos moradores nos diferentes assentamentos estudados $(59,8 \%)$ depende de poços artesianos para obtenção de água tratada, enquanto $13,6 \%$ a obtém da concessionária de água local. Ainda, $54,4 \%$ dos moradores informaram não realizar nenhum tipo de tratamento para a água que consomem e $51,7 \%$ possuem cisterna para o armazenamento de água.

Indicadores socioeconômicos

Para o desenvolvimento de qualquer organização social, o amadurecimento é fator importante no processo de mudança e aprendizagem. Portanto, neste estudo, esperava-se que assentamentos com maior tempo de existência estivessem correlacionados a melhores condições de vida, o que implicaria melhorias de renda, escolaridade e produtividade agropecuária.

No entanto, o tempo de criação dos assentamentos não mostrou relações com fatores sociais, como o aumento da escolaridade dos beneficiários ou com fatores econômicos, como aumento na renda e aumento no número de animais de grande ou pequeno porte criados e/ou de cultivos agrícolas comerciais. Ou seja, uma maior longevidade de um assentamento não necessariamente implica melhorias de renda, escolaridade e produtividade agropecuária. A única relação observada foi entre assentamentos mais antigos e a prática de maior número de atividades de subsistência, tais como a agricultura de grãos (milho e feijão), tubérculos (mandioca, macaxeira e batata) e hortaliças, pecuária e a avicultura $(\mathrm{r}=0,36 ; \mathrm{P}<0,05)$. Outros estudos também mostram que a melhoria da renda familiar não é observada com o passar do tempo nas regiões Norte, Nordeste e Sul, provavelmente, em função do baixo nível de escolaridade e baixa efetividade das cooperativas, fatores que determinam substancialmente a melhoria da renda rural e organização política (MONTE \& PEREIRA, 2009). 
Da mesma forma, assentamentos mais antigos não necessariamente são mais privilegiados em termos de programas sociais, aquisição do Bolsa Família, ou na presença em número de indivíduos assalariados ou aposentados. No entanto, foi observada uma relação positiva entre o aumento da renda da família e o aumento no número de aposentados $(\mathrm{r}=0,3935 ; \mathrm{P}<0,05)$, evidenciando uma possível dependência financeira das famílias em relação aos seus idosos. Houve uma relação significativamente negativa entre a renda média e o suporte governamental do Bolsa Família $(\mathrm{r}=-0,4635 ; \mathrm{P}<0,05)$, sugerindo que, quanto menor a renda apresentada pelos assentados, maior o número de beneficiários do Bolsa Família. A implantação do Bolsa Família visa a justamente transferir créditos financeiros a famílias que se encontram em situação de vulnerabilidade, mas também suscita polêmicas em relação à sua efetividade, pois muitos beneficiários continuam a manter baixos salários (MONNERAT et al., 2009). SILVA (2007), por exemplo, defende o aumento no valor dos programas de distribuição de renda, já que esta população é marcada pela falta de oportunidade, somado a estruturas precárias de saúde e educação, tornando a reversão desse quadro uma difícil tarefa. Outros, no entanto, criticam o seu caráter assistencialista, que poderia levar ao comodismo dos beneficiários (MOURA, 2007).

Embora o tempo não tenha sido significativo, a renda dos assentados tendeu a ser maior em assentamentos mais próximos a centros urbanos $(\mathrm{r}=-0,31 ; \mathrm{P}<0,05)$. Um estudo anterior já havia sugerido uma relação campo/cidade bem aceita pelos assentados, pois a proximidade entre os dois tenderia a elevar a renda familiar através de venda de produtos agropecuários em feiras e para programas governamentais como o PNAE (Programa Nacional de Alimentação Escolar) e o PAA (Programa de Aquisição de Alimentos), além da geração de empregos e acesso a melhores estruturas educacionais de nível médio e superior e à saúde (ROESLER et al., 2008). De forma geral, a renda média dos assentados é explicada parcialmente pelo número médio de animais de grande porte existentes e principalmente pelo número médio de indivíduos pensionistas na família (INC $=0,34+0,028 L G+0,21 R T ; \mathrm{P}<0,001 ; \mathrm{r}^{2}=0,4 ; \mathrm{n}=33$ ).

Indicadores ambientais

A idade do assentamento não afeta o tipo de tratamento dado ao resíduo familiar (coletar, queimar, enterrar ou jogar a céu aberto), sugerindo que o tempo de existência não representa mudanças para melhor ou pior nas práticas ambientais em relação ao tratamento dado aos resíduos domésticos pelas famílias assentadas. A maior distância de um assentamento em relação ao centro urbano, no entanto, diminui as chances de um assentamento ter coleta de lixo urbana $(\mathrm{r}=-0,3248 ; \mathrm{P}<0,05)$. Esse nãoé um problema exclusivo de assentamentos. Muitas vezes, a ausência de coleta regular inexiste mesmo nos pequenos centros urbanos da região de estudo. $\mathrm{O}$ tratamento inadequado dado aos resíduos pelo município faz com que haja proliferação de vetores e piore o índice de doenças no meio rural, onde o acesso à saúde também pode ser restrito, o que reverte em custos elevados para a saúde do município (TEIXEIRA \& HELLER, 2005).

Entre os 16 assentamentos que tiveram o seu PRAD avaliado, apenas 10 apresentaram áreas que se enquadravam como APP (Figura 1). Desses assentamentos, a APP do Vale do Lírio encontra-se $100 \%$ desmatada, seguido por Águas Vivas com 67,2\% e Terra Nossa com $61,5 \%$. Já a taxa de desmatamento da RL foi observada em alto grau no assentamento São José II, a qual desmatou $100 \%$ de sua RL após sete anos de fixação na terra, seguida por São João, a qual desmatou 45,0\% em três anos.

A degradação da RL em um assentamento foi marginalmente explicada pelo grau de escolaridade médio das famílias assentadas, havendo uma correlação negativa entre as duas variáveis ( $\mathrm{LRD}=3,03-6,24 \mathrm{ESC}$; $\mathrm{P}=0,08 ; \mathrm{r}^{2}=0,2 ; \mathrm{n}=16$ ), ou seja, quanto menor a escolaridade maior a degradação. Já a degradação da APP foi mais satisfatoriamente explicada pelo fator idade do assentamento, sendo que, quanto mais velho 0 assentamento, maior o seu percentual de degradação (PPD=-0,76+2,24AGE; $\mathrm{P}<0,001 ; \mathrm{r}^{2}=0,4 ; \mathrm{n}=16$ ).

Esses resultados revelam que as taxas de desmatamento são mais altas nas APP's se comparadas às RL's. APP's são áreas de maior fragilidade de risco ambiental em função da vegetação se localizar em encostas (morros e montanhas) e beiras de corpos d'água. O seu desmatamento leva ao aumento do processo de erosão, ou diminui a proteção que exercem contra o assoreamento de rios e corpos d'água (RANIERI, 1998). No entanto, são áreas visadas pela agricultura pela alta fertilidade do solo nas proximidades dos rios (CUNHA\& SILVA, 2002).

Preocupa ainda a falta de manejo nas áreas de RL's, em que assentamentos com diferentes idades de criação apresentaram taxas altíssimas de desmatamento. Estudos indicam que as regiões Sul e Sudeste do Brasil têm os assentamentos com as menores taxas de desmatamento $(4,7 \%$ e $1,8 \%$ respectivamente), ficando o Norte em terceiro lugar $(28,3 \%)$ e o Nordeste em quarto (30,5\%). Nas duas últimas regiões, predomina o padrão de corte e queima, no preparo do solo (INCRA, 2010). Em 4.340 projetos criados entre 1985 e 2001, 


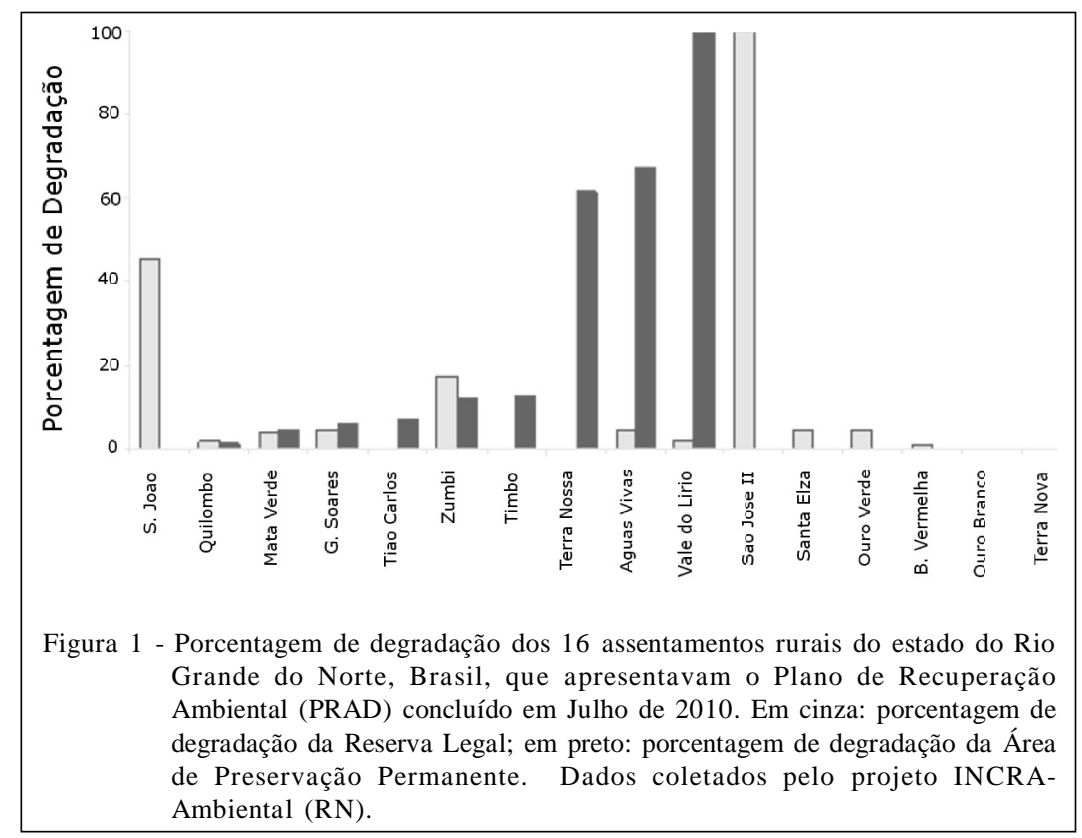

demonstrou-se que as regiões Norte e Nordeste apresentaram os índices mais baixos de qualidade ambiental (STEEG et al., 2006), destacando-se o desmatamento das APP's e RL's.

Nesse contexto de degradação ambiental de áreas, que deveriam estar protegidas, é questionável se propor mudanças no atual Código Florestal (Lei no 4.771/ 1965) que visem à diminuição do tamanho das APP's em $50 \%$ para rios com até $10 \mathrm{~m}$ de largura e a supressão total das RL's para as pequenas propriedades, no intuito de aumentar as terras agricultáveis (RIBEIRO \& FREITAS, 2010). Issoé especialmente inviável por contrariar medidas já adotadas pelo Governo, visando a uma agricultura sustentável, como o programa de restauração de áreas degradadas (INCRA, 2008). Além disso, deve-se considerar o custo dos serviços ecossistêmicos prestados pelas áreas preservadas. Estas aumentam a produtividade local através dos polinizadores, melhoram o clima, diminuem os riscos de erosãoe deslizamentos de encostas, mantêm a fertilidade dos solos e disponibilizam recursos (exemplos: mel, plantas medicinais e frutas) (IMPERATRIZ \& NUNES, 2010). Por sua vez, é preciso gerar mais conhecimentos acerca dos indicadores ambientais, para se construir indicadores eficazes que apontem os diferentes tipos de dificuldades encontradas, no intuito de mitigar tais problemas.

Finalmente, vale ressaltar que os problemas ambientais aqui apresentados não são exclusividades de assentamentos rurais provenientes de programas governamentais. Ausência de tratamento adequado de resíduos domiciliares e degradação de áreas legalmente protegidas são problemas observados em todas as regiões do país, inclusive em algumas regiões urbanas (NUNESMAIA, 2002). Ressalta-se, no entanto, o fato de que assentamentos deveriam ser teoricamente planejados e assistidos pelos órgãos competentes para atingir seus objetivos de diminuição de conflitos e desigualdades sociais.

\section{CONCLUSÃO}

Políticas públicas voltadas para o processo de Reforma Agrária ainda são deficientes na região nordeste brasileira. Isso, quando atrelado às maiores taxas de analfabetismo do país, dificulta o processo de gestão e cooperativismo, necessários à emancipação econômica dos assentamentos. No entanto, nos casos específicos aqui analisados, assentamentos tendem a melhorar a segurança alimentar, especialmente com o passar do tempo, pois se observou um maior número de cultivos voltados para a subsistência em assentamentos mais antigos.

Já a insustentabilidade ambiental desses assentamentos tem sua origem em práticas culturais inclusive anteriores à existência destes. Tal insustentabilidade parece ser afetada pela baixa escolaridade, tempo de existência do assentamento e muito provavelmente pela falta de orientação para um bom manejo dos recursos naturais. Outro fator importante a ser considerado nessas conclusões é a não mensuração do tamanho das APP's e RL's na época 
de criação dos assentamentos mais antigos, o que impede de estabelecer relações lineares concretas entre o desmatamento e o tempo de existência do assentamento, pois muitas áreas poderiam já estar desmatadas quando convertidas em assentamento rural.

O processo de Reforma Agrária não deve ser generalizado, devendo-se avaliar os indicadores socioambientais locais em função de suas peculiaridades e das suas potencialidades. Para isso, é necessário resguardar os recursos ambientais em consonância com a legislação estabelecida, diminuindo os danos ambientais desse processo e assegurandose a manutenção de serviços ecossistêmicos essenciais ao funcionamento das próprias práticas agrícolas. O fator histórico e cultural nem sempre é o gatilho para o desmatamento, e sim o crescimento de assentamentos sem estruturas pré-estabelecidas e sem apoio técnico pós-estabelecimento.

\section{AGRADECIMENTOS}

Ao Projeto Incra-Ambiental, por ter gentilmente cedido os seus dados. A todos os agricultores participantes deste projeto. A um revisor anônimo que contribuiu para o esclarecimento de diversos pontos deste artigo.

\section{REFERÊNCIAS}

ALMEIDA, J. Da ideologia do progresso à idéia de desenvolvimento (rural) sustentável. In: ALMEIDA. J.; NAVARRO, Z. Reconstruindo a agricultura: idéias e ideais na perspectiva do desenvolvimento rural sustentável. 2.ed. Porto Alegre: UFRGS, 1998. p.33-55.

BERGAMASCO, S.M.P.P. A realidade dos assentamentos rurais por detrás dos números. Estudos Avançados, v.11, n.13, p.3749, 1997.

CARDOSO, R. Sustentabilidade, o desafio das Políticas Sociais no século 21. São Paulo em Perspectiva, v.18, n.2, p.42-48, 2004.

CUNHA, H.W.A.P.; SILVA, A.C. Caracterização sócioambiental do Rio Mearim na cidade de Ararí-MA. Revista Ecossistema, v.27, n.1, 2, p.31-36, 2002.

GEHLEN, I. Políticas públicas e desenvolvimento social rural. São Paulo em Perspectiva, v.18, n.2, p.95-103, 2004.

GUANZIROLI, C.E. Reforma agrária e globalização da economia - $\mathrm{O}$ caso do Brasil. Projeto de cooperação técnica. Rio de Janeiro: INCRA/FAO, 2001. p.24.

GUANZIROLI, C.E. Principais indicadores sócio-econômicos dos assentamentos de reforma agrária. In: ROMEIRO, A. et al. (Org.). Reforma agrária: produção, emprego e renda. Petrópolis: Vozes. 1994. p.13-68.

IMPERATRIZ-FONSECA, V.L.; NUNES-SILVA, P. As abelhas, os serviços ecossistêmicos e o Código Florestal Brasileiro. Biota Neotrop,
2010. Disponível em: <http://www.biotaneotropica.org.br/v10n4/pt/ abstract?article+bn00910042010>. Acesso em: 14 jun. 2012.

INSTITUTO NACIONAL DE COLONIZAÇÃO E REFORMA AGRÁRIA. Avaliação da qualidade dos assentamentos rurais, 2010. Disponível em: <http://pqra.incra.gov.br/>. Acesso em: 10 mar. 2011.

Plano de ação ambiental, 2008. Disponível em: <http://www.incra.gov.br>. Acesso em: 05 jul. 2009.

MAFIOLETTI, T.M. Desnutrição energético-proteica e formas de apropriação do solo: estudo de caso nas áreas de reforma agrária do estado do Paraná. 1997. 95f. Dissertação (Mestrado em Saúde Coletiva) - Universidade Estadual de Londrina, PR.

MONNERAT, G.L. et al. Um estudo regional dos determinantes da geração de renda e construção da cidadania nos projetos de assentamentos. Revista de Economia e Sociologia Rural, v.47, n.4, p.1023-1040, 2009.

MOURA, P.G.M. Bolsa família: projeto social ou marketing político? Revista Katálysis, v.10, n.4, p.115-122, 2007.

NUNESMAIA, M.F. A gestão de resíduos urbanos e suas limitações. Revista Baiana de Tecnologia, v.17, n.1, p.120129, 2002.

RANIERI, S.B.L. et al. Aplicação de índice comparativo na avaliação do risco de degradação das terras. Revista Brasileira de Ciência do Solo, v.22, n.4, p.751-760, 1998.

RIBEIRO, K.T.; FREITAS, L. Impactos potenciais das alterações no Código Florestal sobre a vegetação de campos rupestres e campos de altitude. Biota Neotropica, v.10, n.4, p.239-246, 2010.

ROESLER, D.A. et al. Limites e potencialidade para o desenvolvimento socioambiental: um estudo em comunidade rurais no sul da região metropolitana de Curitiba-PR. In: ENANPAS, 4, 1998, Santa Maria, RS. Anais ENANPAS... Brasília: Associação Nacional de Pesquisa e Pós-graduação em Ambiente e Sociedade, 1998. Disponível em: <http://www.anppas.org.br/encontro4/cd/ gt1.html>. Acesso em: 14 ago. 2012.

SILVA, M.O. da S. O bolsa família: problematizando questões centrais na política de transferência de renda no Brasil. Ciência e Saúde Coletiva, v.12, n.6, p.1429-1439, 2007.

SPAROVEK, G. A qualidade dos assentamentos de reforma agrária brasileira/ SPAROVEK, G. (Org.). São Paulo: Páginas \& Letras, 2003. 167p.

STEEG, J.A.V. et al. Environmental impact of the Brazilian Agrarian Reform process from 1985 to 2001. Scientia Agricola, v.63, n.2, p.176-183, 2006.

TEIXEIRA, J.C.; HELLER. L. Fatores ambientais associados à diarréia infantil diarréia em áreas de assentamentos subnormal em Juiz de Fora. Revista Brasileira de Saúde Materno Infantil, v.5, n.5, p.449-455, 2005. 